\title{
Predicting the occurrence of venous thromboembolism: construction and verification of Risk Warning Model
}

\section{Chen Shen}

Affiliated Hospital of Nantong University

\section{Binqian Ge}

Suzhou Vocational Health College

\section{Xiaoqin Liu}

Affiliated Hospital of Nantong University

\section{Hao Chen}

Affiliated Hospital of Nantong University

Yi Qin

Affiliated Hospital of Nantong University

Hongwu Shen ( $\nabla 1092520947 @ q q . c o m$ )

Affiliated Hospital of Nantong University https://orcid.org/0000-0002-9304-5384

\section{Research article}

Keywords: Venous thromboembolism, Risk factors, Caprini scale, Logistic regression analysis, Predictive model

Posted Date: March 30th, 2020

DOI: https://doi.org/10.21203/rs.2.20597/v2

License: (9) This work is licensed under a Creative Commons Attribution 4.0 International License.

Read Full License

Version of Record: A version of this preprint was published at BMC Cardiovascular Disorders on May 27th, 2020. See the published version at https://doi.org/10.1186/s12872-020-01519-9. 


\section{Abstract}

Background: The onset of venous thromboembolism is insidious and the prognosis is poor. In this study, we aimed to construct a VTE risk early warning model and explore the clinical application value of the VTE risk early warning model. Methods: Preliminary construction of the VTE risk warning model was carried out according to the independent risk warning indicators of VTE screened by Logistic regression analysis in previous studies. The truncated value of screening VTE was obtained and the model was evaluated. ROC curve analysis was used to compare the test performance of Caprini risk assessment scale and VTE risk warning model on VTE. The validation data set was established, and the cut-off value of the VTE risk warning model was used to evaluate the test effectiveness of the model for VTE patients with validation data set. Results: The VTE risk warning model is $p=e x /(1+e x), x=-4.840+2.557$ • $\mathrm{X} 10(1)+1.432 \cdot \mathrm{X} 14(1)+2.977 \cdot \mathrm{X} 15(1)+3.445 \cdot \mathrm{X} 18(1)+1.086 \cdot \mathrm{X} 25(1)+0.249 \cdot \mathrm{X} 34+0.282 \cdot \mathrm{X} 41$. ROC curve results show that: AUC $(95 \% \mathrm{Cl})$, cutoff value $(95 \% \mathrm{Cl})$, accuracy, Youden index $(95 \%)$, sensitivity, specificity and other evaluation indexes, Caprini risk assessment scale is $0.596(0.552,0.638)$, $>5(>4,>5), 61.3 \%, 0.226(0.167,0.290), 26.07 \%, 96.50 \%$, VTE risk warning model is $0.960(0.940,0.976)$, $>0.438$ (>0.263), respectively. $>, 0.504), 92.2 \%, 0.844(0.789,0.879), 92.61 \%, 91.83 \%$, with statistically significant differences $(Z=14.521, P<0.0001)$. The accuracy and Youden index of VTE screening using VTE risk warning model were $81.8 \%$ and $62.5 \%$, respectively. Conclusions: VTE risk warning model has high accuracy in predicting the occurrence of VTE in hospitalized patients, and its test performance is higher than Caprini risk assessment scale. It also has high test performance for VTE in external population.

\section{Background}

Venous thromboembolism (VTE) is a common disease with high morbidity and mortality [1], including deep vein thrombosis (DVT) and pulmonary embolism (PE), is the third most common cardiovascular disorder. The incidence of VTE is concealed and the prognosis is poor. At the same time, its incidence rate is increasing year by year, and it shows a trend of younger age[2-3]. Despite many affecting factors of VTE[4-8], early identification and early intervention of VTE has always been our focus[9-10]. Studies have shown a lack of clinical VTE care standards for inpatients and the low VTE prevention rate of patients, which indicate that further improvement is needed[11]. Approximately $50 \%$ of VTEs are provoked by immobilization, trauma, surgery, or hospitalization in the antecedent 3 months[12-15]. And $20 \%$ are associated with cancer while $30 \%$ are unprovoked[16-18]. VTE has many risk factors which are constantly being updated[19-25]. Currently, Caprini Risk Assessment Scale is widely used in clinical practice. However, genetic and environmental differences between Western and Chinese population limit the validity of Caprini Risk Assessment Scale in Chinese patients. Medical records which contain rich information about disease progression, are useful in mining new risk factors related to VTE patients. Each patient will undergo a series of laboratory tests upon admission, and the blood test indicators of VTE patients will be abnormal to varying degrees[26-28]. The timely detection of these abnormal changes will help to assess the risk of VTE occurrence and enable early warning and intervention. Therefore, this 
study which was based on the characteristics of VTE patients in China screened out the VTE risk early warning indicators other than the traditional scale, and established a VTE Risk Warning Model. This study was to effectively achieve the primary prevention of VTE and provide a scientific theory for VTE prevention.

\section{Methods}

\section{Study population}

A total of 257 patients with VTE who were diagnosed with VTE and met the inclusion and exclusion criteria from January 1, 2017 to June 30, 2018 were included.(1) VTE inclusion criteria: patients diagnosed with VTE during hospitalization, age $\geq 18$ years, hospitalization time $\geq 2$ days (48 h), and clinical medical records completed. (2) VTE exclusion criteria: patients who had VTE before admission, those with superficial vein thrombosis, and those who used anticoagulants. For group matching, 257 nonVTE patients of the same period who were admitted to the same department, age, disease course and other general data were selected as the control group and set as the modeling data set. In addition, we selected 63 VTE patients and 85 non-VTE patients from July 1, 2018 to December 31, 2018, and established a validation data set. The inclusion criteria were the same as those of the modeling data set. This clinical research protocol complies with the relevant provisions of the Helsinki Declaration on the protection of the rights and interests of subjects.

\section{Study design}

The the modeling data set were analyzed by $\mathrm{T} / c^{2}$ test and then by Logistic regression. According to the independent risks of VTE screened by Logistic regression analysis, a VTE risk warning model was constructed, and the cut-off value of screening VTE was obtained. The validation data set was established, and the cut-off value of the VTE risk warning model was used to verify the screening efficacy of the VTE risk warning model for patients with VTE in the validation data set.

\section{Assessments}

Since Logistic regression with maximum likelihood method for regression coefficient estimation is sensitive to multicollinearity, in the case of a high degree of multicollinearity, it will lead to a large change in coefficient estimation value or symbol. Therefore, multicollinearity analysis is needed before multivariate analysis. The variance expansion coefficient (VIF) diagnostic method is one of the commonly used multicollinearity analysis methods. Generally, VIF> 5 indicates the existence of multicollinearity. If the number of samples is large, VIF> 10 indicates the existence of multicollinearity.

The gold standard of diagnose is used to distinguish the experimental group and the control group. The effectiveness of the VTE risk early warning model was evaluated using the four-division table of diagnostic data. The evaluation indicators mainly include Sensitivity (Sen), Specificity (Spe), Accuracy (Acc), and Youden Index (Youden's Index). A widely accepted receiver operating characteristic curve 
(ROC) criterion is that area under curve (AUC) is below 0.6 for low discrimination, 0.6 to 0.75 is for medium discrimination, and above 0.75 is for high discrimination. The high AUC represent high model accuracy.

\section{Statistical analysis}

Statistical analysis was performed using SPSS 20.0. In univariate analysis, all statistical variables of the VTE group were compared with the corresponding variables of the control group in order to determine the $P$ value of all statistical variables. Measurement data is described by $(X \pm S)$, and count data is described by frequency and frequency. The categorical variables are tested by $c^{2}$ test, the calibration is performed by $c^{2}$ test or Fisher exact probability method, and the continuous variables are tested by $t$ test or $t^{2}$ test. Logistic regression was used in the multivariate analysis. The variables in the model are selected based on the results of the univariate analysis. Variables in the univariate analysis that are hypothesis-tested $\mathrm{P}$ $<0.3$ (in order to prevent missing possible early warning indicators) and are consistent with previous literature reports and clinical experience are included in the follow-up Multivariate. In order to simplify the model, stepwise regression method was adopted to screen model variables. The regression method was set as "Forward: LR", and the test level $a=0.05$ for introducing variables into the model and 0.10 for removing variables from the model was specified. Logistic regression was used to obtain the regression coefficient, standard error, chi-square value of Wald, $P$ value, corresponding OR value and $95 \%$ confidence interval of the possible predictors. The independent risk warning index of VTE screened by Logistic regression analysis was used to construct the VTE risk warning model, and the screening efficiency of the VTE risk warning model was evaluated and compared by ROC. External validation of VTE risk warning model was carried out by using the four-division table of diagnostic data to evaluate its test effectiveness. $P<0.05$ was considered statistically significant.

\section{Results}

\section{Single factor analysis of risk warning indicators of venous thromboembolism risk}

According to relevant literature and clinical practice, the VTE risk warning indicators which are not included in the Caprini score scale mainly include four parts: (1) General indicators, mainly including gender, patient origin, nationality, payment methods, length of stay (days); (2) Related indicators of current medical history, including 17 variables such as cough, expectoration, hemoptysis, dyspnea, pleural chest pain, cyanosis, pain in the precardiac area, palpitations, shortness of breath after exertion, chest tightness, shortness of breath, syncope with unknown cause, pleural effusion, unilateral lower limb Pain, deep venous tenderness in the lower limbs, pigmentation in the lower limbs, walking fatigue in the lower limbs, and increased local skin temperature in the lower limbs; (3) Relevant indicators of previous history, mainly including 7 variables such as hypertension, diabetes, smoking, systemic connective tissue disease, renal insufficiency, liver disease (hepatitis or liver damage), anemia; (4) The relevant indexes of the laboratory inspection items, mainly including 11 variables such as prothrombin time (PT), thrombin time (TT), activated partial thrombin time (APTT), Fibrinogen (FIB), Fibrinogen Degradation Product 
(FDP), International Normalized Ratio (INR), D-Dimerization , Albumin, platelet count, white blood cell count, number of red blood cells. In addition, we included the Caprini score as a risk warning indicator in the univariate analysis. The detailed results are shown in Table 1.

\section{Multivariate analysis of early risk warning indicators of venous thromboembolism}

Univariate analysis was performed on 41 variables, of which there were 15 variables with statistical significance of $\mathrm{P}<0.05$. In order to not omit possible VTE risk early warning related variables, increase the sensitivity of the risk early warning model and allow more possible variables to be included in the variable, the variables with $\mathrm{P}<0.3$ in the univariate analysis or consistented with literature reports and clinical experience were included in the subsequent multivariate analysis. Therefore, a total of 28 variables were included. After colinear analysis, all variables had VIF less than 3, it can be considered that there is no co-linearity among VTE risk warning indicators, which can be included in multi-factor logistic regression analysis, as shown in Table 2.

The above 28 variables with $\mathrm{P}<0.3$ were included in Logistic regression analysis, and a total of 7 independent risk warning indicators were screened out, which were pleural chest pain $X_{10}(P<0.001)$, shortness of breath after exercise $X_{14}(P=0.045)$, and shortness of breath $X_{15}(P<0.001)$, unilateral lower extremity pain $X_{18}(P<0.001)$, smoking $X_{25}(P=0.005)$, fibrinogen degradation product $X_{34}(P<0.001)$, Caprini score $X_{41}(P=0.004)$. The logistic regression was used to obtain the regression coefficient, standard error, Wald chi-square value, $\mathrm{P}$ value, its corresponding OR value, and its $95 \%$ confidence interval of the independent risk warning indicators, as shown in Table 3.

\section{Construction of VTE Risk Warning Model}

According to the above results The model independent variable assignment method is shown in Table 4. The final VTE risk warning model is as follows:

$p=e^{x} /\left(1+e^{x}\right)$

$x=-4.840+2.557 \cdot X_{10(1)}+1.432 \cdot X_{14(1)}+2.977 \cdot X_{15(1)}+3.445 \cdot X_{18(1)}+1.086 \cdot X_{25(1)}+0.249 \cdot X_{34}+$ $0.282 \cdot X_{41}$

Where e is the logarithm of natural numbers;

Pleural chest pain $X_{10}$, shortness of breath after exercise $X_{14}$, chest tightness shortness of breath $X_{15}$, unilateral lower extremity pain $\mathrm{X}_{18}$, smoking $\mathrm{X}_{25}$ and other variables are binary values (not specific medical history, 1 for yes, 0 for none). The unit of fibrinogen degradation product $\left(X_{34}\right)$ was $(\mu \mathrm{g} / \mathrm{ml})$. Caprini score $\left(\mathrm{X}_{41}\right)$ is based on Caprini risk assessment scale, with no unit.

\section{Evaluation and comparison of test efficacy of VTE Risk Warning Model}


According to the formula of the VTE risk warning model, the predicted probability of VTE occurrence was calculated useing ROC curve analysis. The area under the ROC curve (AUC) was 0.960 (95\% Cl: 0.940, 0.976), the standard error was 0.009 , and $Z=52.279$. The Hosmer-Lemeshow test (H-L test) was performed on the VTE risk warning model, and the $c 2$ was 55.441 .

Caprini risk assessment scale and VTE risk warning model were used to predict the truncation value (95\% $\mathrm{Cl})$ of VTE, which were $5(4,5), 0.438(0.263,0.504)$, respectively. The sensitivity, specificity, accuracy and Youden index of VTE were predicted as $26.1 \%, 96.5 \%, 61.3 \%, 0.23$ and $92.6 \%, 91.8 \%, 92.2 \%, 0.84$ respectively. The AUC values were 0.596 ( $95 \% \mathrm{Cl}: 0.552,0.638$ ) and 0.960 ( $95 \% \mathrm{Cl}: 0.940,0.976$ ), respectively. The difference between the two groupd was statistically significant $(Z=14.521, P<0.0001)$, as shown in Figure 1.

\section{External validation of VTE Risk Warning Model}

The validation data set included 63 patients with VTE and 85 patients without VTE. There was no significant difference in the distribution of general clinical variables between validation data set and modeling data set $(P>0.05)$, which avoided the deviation of the results due to the uneven distribution of clinical variables.

The validation data set was substituted into the established VTE risk warning model formula to calculate the prediction probability of the occurrence of VTE in each patient, and the truncation value of the model was used to evaluate the prediction efficiency of the validated data set. The sensitivity, specificity, accuracy and Youden index were $77.8 \%, 84.7 \%, 81.8 \%$ and 0.625 , respectively. It indicated that the VTE risk warning model had a higher prediction efficiency both in the external population and external population.

\section{Discussion}

\section{Early warning model of venous thromboembolism risk}

In this study, multivariate logistic regression analysis was performed on general information, medical history data, blood parameters, and Caprini scores of 257 VTE patients to screen out VTE risk warning indicators other than the Caprini assessment scale. A clinical diagnostic model including 4 medical history data, 2 laboratory data, and 1 scale score was developed. The area under ROC curve (AUC) of this model is 0.960 ( $95 \% \mathrm{Cl}: 0.940,0.976)$. A good disease risk prediction model is not only a simple mathematical combination of dependent variables and independent variables, but also the actual clinical significance behind it. Our original intention is to require the prediction model to have high prediction efficiency, differentiation ability and sensitivity. The most used indicator to evaluate the discriminability of prediction models is the AUC, also known as the $\mathrm{C}$ statistic. The larger the AUC, the better the discriminant ability of the prediction model. AUC $<0.6$ is of poor differentiation, $0.6-0.75$ is of certain differentiation ability, and $>0.75$ is of good differentiation ability. This research model had a high prediction efficiency for VTE (AUC=0.960). In this study, a validation data set consisting of 63 cases of 
VTE patients and 85 cases of non-VTE patients was selected for model validation. The accuracy of the VTE risk warning model for VTE prediction was $81.8 \%$. The high AUC of this prediction model may be related to the modeling data of the VTE group and the control group matched according to $1: 1$. Of course, the incidence of VTE is relatively low in the actual clinical process, which makes us need to continuously improve and adjust it in a wider range of later use in order to maximize the clinical value. The sensitivity of this model to VTE early warning is significantly higher than the Caprini risk assessment scale. For VTEs with severe life threats, early identification will benefit the most. Therefore, the high sensitivity of this warning model is in line with our expectations. Although the degree of sensitivity and specific it is often difficult to achieve perfect synchronization state of ideal, the early warning model of VTE specificity was $5 \%$ lower than than Caprini risk assessment scale. It indicated that some of the nonVTE patients with risk factors were identified in advance by some early warning indicators, leading to a certain amount of false positives.

\section{Clinical status of early warning mechanism of venous thromboembolism}

In order to take timely and effective measures to prevent the occurrence or further progress of VTE, clinicians and nurses should be kept informed of the early warning of VTE, including high risk of occurrence and the identification of early stage. There are many methods for the evaluation of clinical VTE, each has a certain scope of application and the results are not very satisfactory. A retrospective single-center study on patients who underwent thoracic surgery showed the areas under the receiver operating characteristic (ROC) curve of Caprini, Rogers, Padua, Khorana were $0.74(\mathrm{P}<0.0001), 0.52$ $(P=0.62), 0.69(P<0.0001), 0.64(P=0.0017)$, respectively[29]. In another study, ROC indicated that the Caprini score showed a significant but moderate relationship to VTE (AUC=0.64; $p=0.004)$ [30]. Other studies have reached similar conclusions[31-33]. Though, many embedded VTE warning software has been developed and integrated with electronic medical record system but this software is mostly based on Caprini Risk Assessment Scale, or Padua Assessment Scale, etc [34-37]. Vyas et al. [38] adopted the analysis way of Ishikawa Fishbone Diagram, and found that main reason for the improper prevention of DVT were the lacks of unified standard specifications, the computerized input system for doctors' orders and effective risk assessment methods [39]. Also, others improved the Caprini Risk Assessment Scale[3132], but a lot of useful information in the electronic medical record system is not really used. These evaluation scales have not passed domestic large-scale clinical certification, and the accuracy and sensitivity of VTE screening are not very high. Therefore, the embedded automatic assessment and early warning system designed based on these scales usually have some inherent deficiencies.

\section{Clinical significance of early warning model for venous thromboembolism}

Considering the prevention and treatment of VTE are hot topic in the medical field, also a difficult point in clinical work. The VTE prediction model are established with the purpose of making accurate assessment and diagnosis of VTE in the first time and avoiding adulterating human factors as much as possible. We know that there is a lot of VTE-related information in the electronic medical record system[27, 33-35, 4042], and this information needs to be further explored and fully utilized in the clinical warning of VTE. The 
VTE risk warning model makes full use of the Caprini risk assessment scale, which is widely used in clinical medicine and surgery, with the important clinical symptoms and signs of VTE patients and laboratory examination indicators, to carry out comprehensive and multi-dimensional comprehensive

warning and achieve higher prediction efficiency. In Chinese medical staff, the work intensity is high, and It is a great challenge to monitor patient's condition consistently. We screen six independent warning indicators except the Caprini score, including pleural chest pain, shortness of breath after exercise, chest tightness shortness of breath, unilateral lower extremity pain, smoking, fibrinogen degradation product. We set up standard terms and capture the records of standard terms in the electronic medical record system in order to establish electronic active alarm system which can prompt doctors and nurses to take timely coping measures. It is of great clinical significance to develop embedded electronic VTE active alarm systems based on VTE risk warning model.

\section{The deficiency and prospect of the research}

This study was unable to avoid the sample selectivity bias caused by the retrospective study. During this study, prothrombin time, D-dimer, and leukocytes in blood biochemical indicators were statistically significant in univariate analysis, but failed to enter the model during multivariate analysis. In addition, several literatures have shown that platelets, inflammatory indicators, and the ratio of certain cell counts are also important in the early warning of VTE. Therefore, many blood biochemical indicators in clinical have potential value in the prediction and warning of VTE, which needs more high-quality studies to prove. This study only explored the newly discovered independent warning indicators of VTE, and the mechanism of each warning indicator needs to be further studied. In addition, due to the limitation of various factors in the single-center study, the all-dimensional and multi-dimensional VTE risk warning model based on a series of clinical comprehensive indicators needs to be constantly improved, verified and promoted in more centers and larger samples.

\section{Conclusions}

In this study, VTE risk warning model includes seven independent risk factors $₫$ pleural chest pain, shortness of breath after exercise, and shortness of breath, unilateral lower extremity pain, smoking, fibrinogen degradation product, Caprini score. It has been verified to have a high early warning effect on VTE in hospitalized patients and has certain clinical application value.

\section{Abbreviations}

VTE: Venous thromboembolism;

ROC: Receiver operating characteristic;

AUC: Area under curve;

DVT: Deep venous thrombosis; 
PE: Pulmonary embolism;

AHA: American heart association;

PTS: Post-thrombotic syndrome;

AT: Anticoagulant proteins;

BMI: Body mass index;

TP: True positive;

FP: False positive;

FN: False negative;

TN: True negative;

Acc: Accuracy;

Sen: Sensitivity;

PR: True Positive Rate;

FNR: False negative rate;

Spe: Specificity;

TNR: True negative rate;

FPR: False positive rate;

LR: Likelihood ratio;

\section{Declarations}

\section{Acknowledgements}

Not applicable.

\section{Author information}

Chen Shen and Binqian Ge contributed equally to this work.

\section{Author details}


${ }^{1}$ Department of Nursing, Affiliated Hospital of Nantong University, 20 Xisi Road, Nantong City, Jiangsu 226000, China. ${ }^{2}$ School of Nursing, Suzhou Vocational Health College, 28 Kehua Road, Suzhou City, Jiangsu 215009, China. ${ }^{3}$ Department of Information, Affiliated Hospital of Nantong University, 20 Xisi Road, Nantong City, Jiangsu 226000, China.

\section{Authors' contributions}

CS, and HWS designed the study and critically appraised the research contents and collected the data. CS and BQG wrote the first draft. HWS, XQL and YQ conducted the systemic review and revised the manuscript. CS and $\mathrm{HC}$ collected the data. All authors contributed to subsequent versions and approved the final manuscript. HWS is the corresponding author.

\section{Corresponding authors}

Correspondence to Hongwu Shen.

\section{Funding}

Social and People's Livelihood Science and Technology Projects of Nantong

NO.MS12018084

\section{Availability of data and materials}

The dataset supporting the conclusions of this article is included within the article.

\section{Ethics approval and consent to participate}

An ethics statement was not required for this work. Data used in the analysis were anonymized. The database was open to the public and did not require any ethical or administrative permission.

\section{Consent for publication}

Not applicable.

\section{Competing interests}

The authors declare that they have no competing interests.

\section{References}

1. Heit JA. Epidemiology of venous thromboembolism. Nat Rev Cardiol.2015;12(8): 464-474.

2. Ma K, Wells P, Guzman C, Anderson D, Blostein M, Hirsch A, Lazo-Langner A, Kovacs MJ, Rodger M, Tagalakis V, Kahn SR. A multicenter prospective study of risk factors and treatment of unusual site thrombosis. Thrombosis Research. 2016;144:100-105. 
3. Virani SS, Alonso A, Benjamin EJ, Bittencourt MS, Callaway CW, Carson AP, Chamberlain AM, Chang AR, Cheng S, Delling FN, et al. Heart Disease and Stroke Statistics-2020 Update: A Report From the American Heart Association. Circulation. 2020;141(9):e139-e596.

4. Wiener RS, Schwartz LM, Woloshin S. Time trends in pulmonary embolism in the United States: evidence of overdiagnosis. Arch Intern Med. 2011;171:831-837.

5. Stein PD, Matta F, Hughes MJ. Home treatment of deep venous thrombosis according to comorbid conditions. Am J Med. 2016; 129:392-397.

6. Stein PD, Matta F, Hughes PG, Hourmouzis ZN, Hourmouzis NP, White RM, Ghiardi MM, Schwartz MA, Moore HL, Bach JA, et al. Home treatment of pulmonary embolism in the era of novel oral anticoagulants. Am J Med. 2016; 129:974-977.

7. Klil-Drori AJ, Coulombe J, Suissa S, Hirsch A, Tagalakis V. Temporal trends in outpatient management of incident pulmonary embolism and associated mortality. Thromb Res. 2018; 161:111-116.

8. White C, Noble SIR, Watson M, Swan F, Allgar VL, Napier E, Nelson A, McAuley J, Doherty J, Lee B, et al. Prevalence, symptom burden, and natural history of deep vein thrombosis in people with advanced cancer in specialist palliative care units (HIDDen): a prospective longitudinal observational study. Lancet Haematol. 2019; 6(2): e79-e88.

9. Stein PD, Beemath A, Olson RE. Trends in the incidence of pulmonary embolism and deep venous thrombosis in hospitalized patients. Am J Cardiol. 2005; 95(12): 1525-1526.

10. Zhang J, Liu ZY. Practice of intervention in management of venous thromboembolism in hospital. Chinese Journal of Hospital Administration. 2017; 144: 100-105.

11. Chinese Medical Association Committee for Prevention and Treatment of Thromboembolism. Construction of a hospital internal venous thromboembolism prevention and management system. Chinese Journal of Hospital Administration. 2013; 29(1): 28-31.

12. Lung BE, Kanjiya $S$, Bisogno $M$, Komatsu DE, Wang ED. Risk factors for venous thromboembolism in total shoulder arthroplasty. JSES Open Access. 2019; 3(3): 183-188.

13. Hereford T, Thrush C, Kimbrough MK. Using Injury Severity Score and Abbreviated Injury Score to Determine Venous Thromboembolism Risk. Cureus. 2019; 11(10): e5977.

14. Kaewborisutsakul A, Tunthanathip T, Yuwakosol P, Inkate S, Pattharachayakul S. Postoperative Venous Thromboembolism in Extramedullary Spinal Tumors. Asian J Neurosurg. 2020; 15(1): 51-58.

15. Kunutsor SK, Barrett MC, Whitehouse MR, Blom AW. Venous thromboembolism following 672,495 primary total shoulder and elbow replacements: Meta-analyses of incidence, temporal trends and potential risk factors. Thromb Res. 2020; 189:13-23.

16. Connolly GC, Francis CW. Cancer-associated thrombosis. Hematology Am Soc Hematol Educ Program. 2013; 2013: 684-691.

17. Timp JF, Braekkan SK, Versteeg HH, Cannegieter SC. Epidemiology of cancer-associated venous thrombosis.Blood. 2013; 122:1712-1723. 
18. Ay C, Pabinger I, Cohen AT. Cancer-associated venous thromboembolism: burden, mechanisms, and management. Thromb Haemost. 2017; 117: 219-230.

19. Kang G, Zhang H. Risk Factors for Venous Thromboembolism. Am J Med. 2019; 132(11): e807.

20. Paulsen B, Skille H, Smith EN, Hveem K, Gabrielsen ME, Brækkan SK, Rosendaal FR, Frazer KA, Gran OV, Hansen JB. Fibrinogen gamma gene rs2066865 and risk of cancer-related venous thromboembolism. Haematologica. 2019 . pii: haematol.2019.224279. doi: 10.3324/haematol.2019.224279. [Epub ahead of print]

21. Klarin D, Busenkell E, Judy R, Lynch J, Levin M, Haessler J, Aragam K, Chaffın M, Haas M, Lindström $S$, et al. Genome-wide association analysis of venous thromboembolism identifies new risk loci and genetic overlap with arterial vascular disease. Nat Genet. 2019; 51(11): 1574-1579.

22. Vella MA, Dumas RP, Chreiman K, Wasser T, Smith BP, Reilly PM, Seamon MJ, Shiroff A. Epidural catheters are associated with an increased risk of venous thromboembolism in trauma. J Thromb Thrombolysis. 2020 Jan 3. doi: 10.1007/s11239-019-02024-3. [Epub ahead of print]

23. Griffin D, Cha S. Cocaine: A Provoking Risk Factor in Venous Thromboembolism. Cureus. 2019; 11(12): e6520.

24. Wei WT, Liu PP, Lin SM, Peng CC, Wang JH, Huang HK, Loh CH. Hypothyroidism and the Risk of Venous Thromboembolism: A Nationwide Cohort Study. Thromb Haemost. 2020; 120(3): 505-514.

25. Akram F, Sadashiv RG. May-Thurner syndrome: an overlooked cause of venous thromboembolism. Med J Aust. 2020 Mar 12. doi: 10.5694/mja2.50548. [Epub ahead of print]

26. Abuduhalike R, Sun J, Zhao L, Mahemuti A. Correlation study of venous thromboembolism with SAA, IL-1, and TNF-a levels and gene polymorphisms in Chinese population. J Thorac Dis. 2019; 11(12): 5527-5534.

27. Bradley M, Shi A, Khatri V, Schobel S, Silvius E, Kirk A, Buchman T, Oh J, Elster E. Prediction of venous thromboembolism using clinical and serum biomarker data from a military cohort of trauma patients. BMJ Mil Health. 2020 Mar 5. pii: bmjmilitary-2019-001393. doi: 10.1136/bmjmilitary-2019001393. [Epub ahead of print]

28. Landy DC, Bradley AT, King CA, Puri L. Stratifying Venous Thromboembolism Risk in Arthroplasty: Do High-Risk Patients Exist? J Arthroplasty. 2020 Jan 16. pii: S0883-5403(20)30031-0. doi: 10.1016/j.arth.2020.01.013. [Epub ahead of print]

29. Tian B, Li H, Cui S, Song C, Li T, Hu B. A novel risk assessment model for venous thromboembolism after major thoracic surgery: a Chinese single-center study. J Thorac Dis. 2019; 11(5): 1903-1910.

30. Frankel J, Belanger M, Tortora J, McLaughlin T, Staff I, Wagner J. Caprini score and surgical times linked to the risk for venous thromboembolism after robotic-assisted radical prostatectomy. Turk J Urol. 2020; 46(2): 108-114.

31. Henke PK. Adding thrombodynamic assessment to Caprini risk assessment to improve venous thromboembolism risk specificity. J Vasc Surg Venous Lymphat Disord. 2020; 8(1): 42-43.

32. Hanh BM, Cuong LQ, Son NT, Duc DT, Hung TT, Hung DD, Giang TB, Hiep NH, Xuyen HTH, Nga NT, et al. Determination of Risk Factors for Venous Thromboembolism by an Adapted Caprini Scoring 
System in Surgical Patients. J Pers Med. 2019; 9(3). pii: E36. doi: 10.3390/jpm9030036.

33. Yang $Y$, Wang $X$, Huang $Y$, Chen N, Shi J, Chen T. Ontology-based venous thromboembolism risk assessment model developing from medical records. BMC Med Inform Decis Mak. 2019; 19(Suppl 4): 151.

34. Zhao HL, Dai LY, Lv M, Shi YM, Zhang SX. Development of Information-based Nosocomial Venous Thromboembolism Risk Management System. Journal of Nursing. 2018; 25(24): 9-12.

35. Owodunni OP, Haut ER, Shaffer DL, Hobson DB, Wang J, Yenokyan G, Kraus PS, Aboagye JK, Florecki $\mathrm{KL}$, Webster KLW, et al. Using electronic health record system triggers to target delivery of a patientcentered intervention to improve venous thromboembolism prevention for hospitalized patients: Is there a differential effect by race? PLoS One. 2020; 15(1): e0227339.

36. Ortel TL, Arnold K, Beckman M, Brown A, Reyes N, Saber I, Schulteis R, Singh BP, Sitlinger A, Thames $\mathrm{EH}$. Design and Implementation of a Comprehensive Surveillance System for Venous Thromboembolism in a Defined Region Using Electronicand Manual Approaches. Appl Clin Inform. 2019; 10(3): 552-562.

37. Yang $Y$, Wang $X$, Huang $Y$, Chen N, Shi J, Chen T. Ontology-based venous thromboembolism risk assessment model developing from medical records. BMC Med Inform Decis Mak. 2019; 19(Suppl 4): 151.

38. Vyas D, Bearelly D, Boshard B. A multidisciplinary quality improvement educational initiative to improve the rate of deep-vein thrombosis prophylaxis. Int J Pharm Pract. 2014; 22 (1): 92-95.

39. Xuan CX, Chen SM, Xie LL, Yang Y, Wang SW. Effect analysis of electronic simplified Caprini risk assessment in the prevention of deep venous thrombosis in ICU patients. Journal of Bengbu Medical College. 2018; 43(3): 394-396.

40. Orsi FA, Lijfering WM, Van der Laarse A, Ruhaak LR, Rosendaal FR, Cannegieter SC, Cobbaert C. Association of apolipoproteins C-I, C-II, C-III and E with coagulation markers and venous thromboembolism risk. Clin Epidemiol. 2019; 11:625-633. doi: 10.2147/CLEP.S196266. eCollection 2019.

41. Avnery O, Martin M, Bura-Riviere A, Barillari G, Mazzolai L, Mahé I, Marchena PJ, Verhamme P, Monreal M, Ellis MH; RIETE Investigators. D-dimer levels and risk of recurrence following provoked venous thromboembolism: findings from the RIETE registry. J Intern Med. 2020; 287(1): 32-41.

42. Kunutsor SK, Mäkikallio TH, Kauhanen J, Voutilainen A, Laukkanen JA. Lipoprotein(a) is not associated with venous thromboembolism risk. Scand Cardiovasc J. 2019; 53(3): 125-132.

\section{Tables}

Table 1 Single factor analysis of VTE risk warning indicators in modeling dataset 


\begin{tabular}{|c|c|c|c|c|c|c|}
\hline \multirow[t]{2}{*}{ Variables } & \multirow[t]{2}{*}{ No. } & & \multirow{2}{*}{$\begin{array}{l}\text { VTE group } \\
\text { n■\%ロor` } X \pm S\end{array}$} & \multirow{2}{*}{ 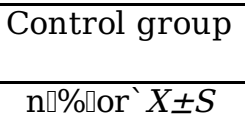 } & \multirow[t]{2}{*}{$c^{2}$ or $t$} & \multirow[t]{2}{*}{$P$} \\
\hline & & & & & & \\
\hline \multirow[t]{2}{*}{ Gender } & $\mathrm{X}_{1}$ & Male & $109 \square 42.4 \square$ & $123 \llbracket 47.9 \square$ & 1.540 & 0.215 \\
\hline & & Female & $148 \square 57.6 \square$ & $134 \square 52.1 \square$ & & \\
\hline \multirow[t]{2}{*}{ Patient source } & $\mathrm{X}_{2}$ & City & $142 \square 55.3 \square$ & $162 \llbracket 63.0 \square$ & 3.221 & 0.073 \\
\hline & & Countryside & 115ロ44.7ロ & 95ロ37.0ロ & & \\
\hline \multirow{2}{*}{ Native place } & $\mathrm{X}_{3}$ & Native & $249 \square 96.9 \square$ & $253 \square 98.4 \square$ & 1.365 & 0.243 \\
\hline & & Non-native & $8 \square 3.1 \square$ & $4 \square 1.6 \square$ & & \\
\hline \multirow[t]{2}{*}{ Payment method } & $\mathrm{X}_{4}$ & $\begin{array}{l}\text { Health } \\
\text { Insurance }\end{array}$ & $111 \square 43.2 \square$ & $138 \square 53.7 \square$ & 5.679 & $0.017^{*}$ \\
\hline & & Self-paying & $146 \square 56.8 \square$ & $119 \square 46.3 \square$ & & \\
\hline Length of stay (days) & $\mathrm{X}_{5}$ & & $13.28 \pm 6.64$ & $13.00 \pm 19.96$ & -2.998 & $0.003^{*}$ \\
\hline \multirow[t]{2}{*}{ Cough } & $\mathrm{X}_{6}$ & No & $218 \square 84.8 \square$ & 197ロ76.7ロ & 5.517 & $0.019^{*}$ \\
\hline & & Yes & $39 \square 15.2 \square$ & 60ロ23.3ロ & & \\
\hline \multirow[t]{2}{*}{ Expectorant } & $\mathrm{X}_{7}$ & No & $227 \square 88.3 \square$ & $246 \square 95.7 \square$ & 9.568 & $0.002^{*}$ \\
\hline & & Yes & $30 \square 11.7 \square$ & $11 \square 4.3 \square$ & & \\
\hline \multirow[t]{2}{*}{ Hemoptysis } & $\mathrm{X}_{8}$ & No & $244 \square 94.9 \square$ & $251 \llbracket 97.7 \square$ & 2.678 & 0.102 \\
\hline & & Yes & $13 \square 5.1 \square$ & $6 \square 2.3 \square$ & & \\
\hline \multirow[t]{2}{*}{ Difficulty breathing } & $\mathrm{X}_{9}$ & No & $250 \square 97.3 \square$ & $253 \square 98.4 \square$ & 0.836 & 0.361 \\
\hline & & Yes & $7 \square 2.7 \square$ & $4 \square 1.6 \square$ & & \\
\hline \multirow[t]{2}{*}{ Pleural chest pain } & $\mathrm{X}_{10}$ & No & $230 \square 89.5 \square$ & $251 \square 97.7 \square$ & 14.28 & $\square 0.001^{*}$ \\
\hline & & Yes & $27 \square 10.5 \square$ & $6 \square 2.3 \square$ & & \\
\hline \multirow[t]{2}{*}{ Cyanosis } & $\mathrm{X}_{11}$ & No & $244 \square 94.9 \square$ & $254 \llbracket 98.8 \square$ & 6.451 & $0.011^{*}$ \\
\hline & & Yes & $13 \square 5.1 \square$ & $3 \square 1.2 \square$ & & \\
\hline \multirow[t]{2}{*}{ Anterior cardiac pain } & $\mathrm{X}_{12}$ & No & $250 \square 97.3 \square$ & $255 \square 99.2 \square$ & 1.809 & 0.176 \\
\hline & & Yes & $7 \square 2.7 \square$ & $2 \square 0.8 \square$ & & \\
\hline \multirow[t]{2}{*}{ Palpitations } & $\mathrm{X}_{13}$ & No & $251 \square 97.7 \square$ & $252 \square 98.1 \square$ & 0.093 & 0.761 \\
\hline & & Yes & $6 \square 2.3 \square$ & $5 \square 1.9 \square$ & & \\
\hline \multirow[t]{2}{*}{ Shortness of breath after exertion } & $\mathrm{X}_{14}$ & No & $245 \square 95.3 \square$ & $252 \square 98.1 \square$ & 2.981 & 0.084 \\
\hline & & Yes & $12 \square 4.7 \square$ & $5 \square 1.9 \square$ & & \\
\hline \multirow{2}{*}{$\begin{array}{c}\text { Chest tightness and shortness of } \\
\text { breath }\end{array}$} & $\mathrm{X}_{15}$ & No & $184 \square 71.6 \square$ & $244 \llbracket 94.9 \square$ & 50.272 & $\square 0.001^{*}$ \\
\hline & & Yes & $73 \llbracket 28.4 \square$ & $13 \square 5.1 \square$ & & \\
\hline Unexplained syncope & $\mathrm{X}_{16}$ & No & $238 \square 92.6 \square$ & $254 \llbracket 98.8 \square$ & 12.157 & $\square 0.001^{*}$ \\
\hline
\end{tabular}




\begin{tabular}{|c|c|c|c|c|c|c|}
\hline & & Yes & $19 \square 7.4 \square$ & $3 \square 1.2 \square$ & & \\
\hline Pleural effusion & $\mathrm{X}_{17}$ & No & $241 \square 93.8 \square$ & $247 \square 96.1 \square$ & 1.458 & 0.227 \\
\hline & & Yes & $16 \square 6.2 \square$ & $10 \square 3.9 \square$ & & \\
\hline Unilateral lower limb pain & $\mathrm{X}_{18}$ & No & $201 \square 78.2 \square$ & $255 \square 99.2 \square$ & 56.671 & {$\left[0.001^{*}\right.$} \\
\hline & & Yes & $56 \square 21.8 \square$ & $2 \square 0.8 \square$ & & \\
\hline Deep vein tenderness in lower limbs & $\mathrm{X}_{19}$ & No & $253 \square 98.4 \square$ & $256 \square 99.6 \square$ & 0.808 & 0.369 \\
\hline & & Yes & $4 \square 1.6 \square$ & $1 \square 0.4 \square$ & & \\
\hline Lower extremity pigmentation & $\mathrm{X}_{20}$ & No & $255 \square 99.2 \square$ & $257 \square 100 \square$ & 0.502 & 0.479 \\
\hline & & Yes & $2 \square 0.8 \square$ & $0 \square 0 \square$ & & \\
\hline Lower limb walking fatigue & $\mathrm{X}_{21}$ & No & $256 \square 99.6 \square$ & $254 \llbracket 98.8 \square$ & 0.252 & 0.616 \\
\hline & & Yes & $1 \square 0.4 \square$ & $3 \square 1.2 \square$ & & \\
\hline Local lower skin temperature increase & $\mathrm{X}_{22}$ & No & $252 \square 98.1 \square$ & $256 \square 99.6 \square$ & 1.518 & 0.218 \\
\hline & & Yes & $5 \square 1.9 \square$ & $1 \square 0.4 \square$ & & \\
\hline Hypertension & $\mathrm{X}_{23}$ & No & $169 \square 65.8 \square$ & 197ロ76.7ロ & 7.439 & $0.006^{*}$ \\
\hline & & Yes & $88 \square 34.2 \square$ & $60 \square 23.3 \square$ & & \\
\hline Diabetes & $\mathrm{X}_{24}$ & No & $231 \square 89.9 \square$ & $240 \square 93.4 \square$ & 2.056 & 0.152 \\
\hline & & Yes & $26 \square 10.1 \square$ & $17 \square 6.6 \square$ & & \\
\hline Smoking & $\mathrm{X}_{25}$ & No & $200 \square 77.8 \square$ & $217 \square 84.4 \square$ & 3.672 & 0.055 \\
\hline & & Yes & $57 \square 22.2 \square$ & $40 \square 15.6 \square$ & & \\
\hline Systemic connective tissue disease & $\mathrm{X}_{26}$ & No & $255 \square 99.2 \square$ & $252 \square 98.1 \square$ & 0.579 & 0.447 \\
\hline & & Yes & $2 \square 0.8 \square$ & $5 \square 1.9 \square$ & & \\
\hline Renal insufficiency & $\mathrm{X}_{27}$ & No & $248 \square 96.5 \square$ & $254 \square 98.8 \square$ & 3.072 & 0.08 \\
\hline & & Yes & $9 \square 3.5 \square$ & $3 \square 1.2 \square$ & & \\
\hline Liver disease & $\mathrm{X}_{28}$ & No & $234 \square 91.1 \square$ & $220 \square 85.6 \square$ & 2.641 & 0.104 \\
\hline & & Yes & $23 \square 8.9 \square$ & $37 \square 14.4 \square$ & & \\
\hline anemia & $\mathrm{X}_{29}$ & No & $246 \square 95.7 \square$ & $250 \square 97.3 \square$ & 0.921 & 0.337 \\
\hline & & Yes & $11 \square 4.3 \square$ & 7 प2.7ロ & & \\
\hline $\mathrm{PT} \square \mathrm{s} \square$ & $\mathrm{X}_{30}$ & & $12.95 \pm 7.29$ & $12.66 \pm 7.73$ & 0.438 & 0.662 \\
\hline $\mathrm{TT} \square \mathrm{s} \square$ & $\mathrm{X}_{31}$ & & $18.28 \pm 3.75$ & $17.72 \pm 1.58$ & 2.206 & $0.028^{*}$ \\
\hline $\mathrm{APTT} \rrbracket \mathrm{s} \square$ & $\mathrm{X}_{32}$ & & $29.47 \pm 6.76$ & $30.20 \pm 5.94$ & -1.300 & 0.194 \\
\hline $\mathrm{FIB} \square \mathrm{g} / \mathrm{L} \square$ & $\mathrm{X}_{33}$ & & $2.84 \pm 0.84$ & $2.83 \pm 0.89$ & 0.131 & 0.896 \\
\hline FDP & $\mathrm{X}_{34}$ & & $23.16 \pm 28.85$ & $5.28 \pm 5.78$ & 9.742 & {$\left[0.001^{*}\right.$} \\
\hline INR & $\mathrm{X}_{35}$ & & $1.15 \pm 1.23$ & $1.09 \pm 0.81$ & 0.653 & 0.514 \\
\hline
\end{tabular}




$\begin{array}{cccccc}\text { D-Dimer }(\mathrm{mg} / \mathrm{L}) & \mathrm{X}_{36} & 8.55 \pm 14.37 & 1.37 \pm 2.14 & 7.923 & \square 0.001^{*} \\ \text { albumin }(\mathrm{g} / \mathrm{L}) & \mathrm{X}_{37} & 36.88 \pm 5.05 & 37.01 \pm 5.10 & -0.290 & 0.772 \\ \text { Platelet }\left(* 10^{9} / \mathrm{L}\right) & \mathrm{X}_{38} & 193.57 \pm 74.38 & 188.94 \pm 81.93 & 0.671 & 0.503 \\ \mathrm{WBC}\left(* 10^{9} / \mathrm{L}\right) & \mathrm{X}_{39} & 7.44 \pm 2.81 & 6.42 \pm 3.27 & 3.793 & \square 0.001^{*} \\ \mathrm{RBC}\left(* 10^{9} / \mathrm{L}\right) & \mathrm{X}_{40} & 4.43 \pm 3.66 & 4.23 \pm 0.64 & 0.863 & 0.389 \\ \text { Caprini score } & \mathrm{X}_{41} & 4.60 \pm 2.72 & 3.56 \pm 1.13 & 5.661 & \square 0.001^{*}\end{array}$

Table2 Colinearity analysis of 28 VTE risk warning indicators including multivariate analysis

\begin{tabular}{|c|c|c|c|c|c|}
\hline Variables & & VIF & Variables & & VIF \\
\hline Gender & $\mathrm{X}_{1}$ & 1.406 & Pleural effusion & $\mathrm{X}_{17}$ & 1.134 \\
\hline Patient source & $\mathrm{X}_{2}$ & 2.266 & Unilateral lower limb pain & $\mathrm{X}_{18}$ & 1.205 \\
\hline Native place & $\mathrm{X}_{3}$ & 1.096 & Local lower skin temperature increase & $\mathrm{X}_{22}$ & 1.062 \\
\hline Payment method & $\mathrm{X}_{4}$ & 1.123 & Hypertension & $\mathrm{X}_{23}$ & 1.146 \\
\hline Length of stay (days) & $\mathrm{X}_{5}$ & 2.343 & Diabetes & $\mathrm{X}_{24}$ & 1.113 \\
\hline Cough & $\mathrm{X}_{6}$ & 2.322 & Smoking & $\mathrm{X}_{25}$ & 1.402 \\
\hline Expectorant & $\mathrm{X}_{7}$ & 2.302 & Renal insufficiency & $\mathrm{X}_{27}$ & 1.054 \\
\hline Hemoptysis & $\mathrm{X}_{8}$ & 1.056 & Liver disease & $\mathrm{X}_{28}$ & 1.065 \\
\hline Pleural chest pain & $\mathrm{X}_{10}$ & 1.122 & $\mathrm{TT} \llbracket \mathrm{s} \square$ & $\mathrm{X}_{31}$ & 1.132 \\
\hline Cyanosis & $\mathrm{X}_{11}$ & 1.061 & APTT\s $\square$ & $\mathrm{X}_{32}$ & 1.081 \\
\hline Anterior cardiac pain & $\mathrm{X}_{12}$ & 1.045 & FDP & $\mathrm{X}_{34}$ & 1.767 \\
\hline Shortness of breath after exertion & $\mathrm{X}_{14}$ & 1.040 & D-Dimer (mg/L) & $\mathrm{X}_{36}$ & 1.765 \\
\hline Chest tightness and shortness of breath & $\mathrm{X}_{15}$ & 1.148 & $\mathrm{WBC}\left(* 10^{9} / \mathrm{L}\right)$ & $\mathrm{X}_{39}$ & 1.138 \\
\hline Unexplained syncope & $\mathrm{X}_{16}$ & 1.106 & Caprini score & $\mathrm{X}_{41}$ & 1.143 \\
\hline
\end{tabular}

Table3 Logistic regression parameter estimation of patients in VTE group and control group 


\begin{tabular}{|c|c|c|c|c|c|c|c|}
\hline Variables & $\begin{array}{c}\text { Point } \\
\text { estimation }\end{array}$ & $\begin{array}{l}\text { Standard } \\
\text { error }\end{array}$ & $\begin{array}{c}\text { Wald chi-square } \\
\text { values }\end{array}$ & $P$ & $\begin{array}{l}\text { OR value point } \\
\text { estimation }\end{array}$ & $\begin{array}{c}\text { Lower } \\
\text { interval }\end{array}$ & $\begin{array}{l}\text { Upper } \\
\text { interval }\end{array}$ \\
\hline$X_{10}$ & 2.557 & 0.624 & 16.800 & 00.001 & 12.893 & 3.797 & 43.784 \\
\hline$X_{14}$ & 1.432 & 0.713 & 4.029 & 0.045 & 4.185 & 1.034 & 16.935 \\
\hline$X_{15}$ & 2.977 & 0.420 & 50.344 & $\square 0.001$ & 19.622 & 8.623 & 44.653 \\
\hline$X_{18}$ & 3.445 & 0.882 & 15.274 & $\square 0.001$ & 31.352 & 5.571 & 176.454 \\
\hline$X_{25}$ & 1.086 & 0.384 & 8.023 & 0.005 & 2.963 & 1.397 & 6.284 \\
\hline$X_{34}$ & 0.249 & 0.024 & 106.673 & $\square 0.001$ & 1.282 & 1.223 & 1.344 \\
\hline$X_{41}$ & 0.282 & 0.099 & 8.184 & 0.004 & 1.326 & 1.093 & 1.608 \\
\hline
\end{tabular}

Table4 The way to evaluate the value of the clinical variable of the VTE risk warning model

\begin{tabular}{ccc}
\hline Clinical variables & No. & Assignment \\
\hline Pleural chest pain & $\mathrm{X}_{10}$ & No=0 $\square 1=$ Yes \\
shortness of breath after fatigue & $\mathrm{X}_{14}$ & No $=0 \square 1=$ Yes \\
chest dull shortness of breath & $\mathrm{X}_{15}$ & No $=0 \square 1=$ Yes \\
unilateral lower limb pain & $\mathrm{X}_{18}$ & No $=0 \square 1=$ Yes \\
smoking & $\mathrm{X}_{25}$ & No $=0 \square 1=$ Yes \\
FDP & $\mathrm{X}_{34}$ & Continuity variable \\
Caprini score & $\mathrm{X}_{41}$ & Continuity variable \\
Outcome variables & $\mathrm{Y}$ & The control group =0 \\
\hline
\end{tabular}

\section{Figures}




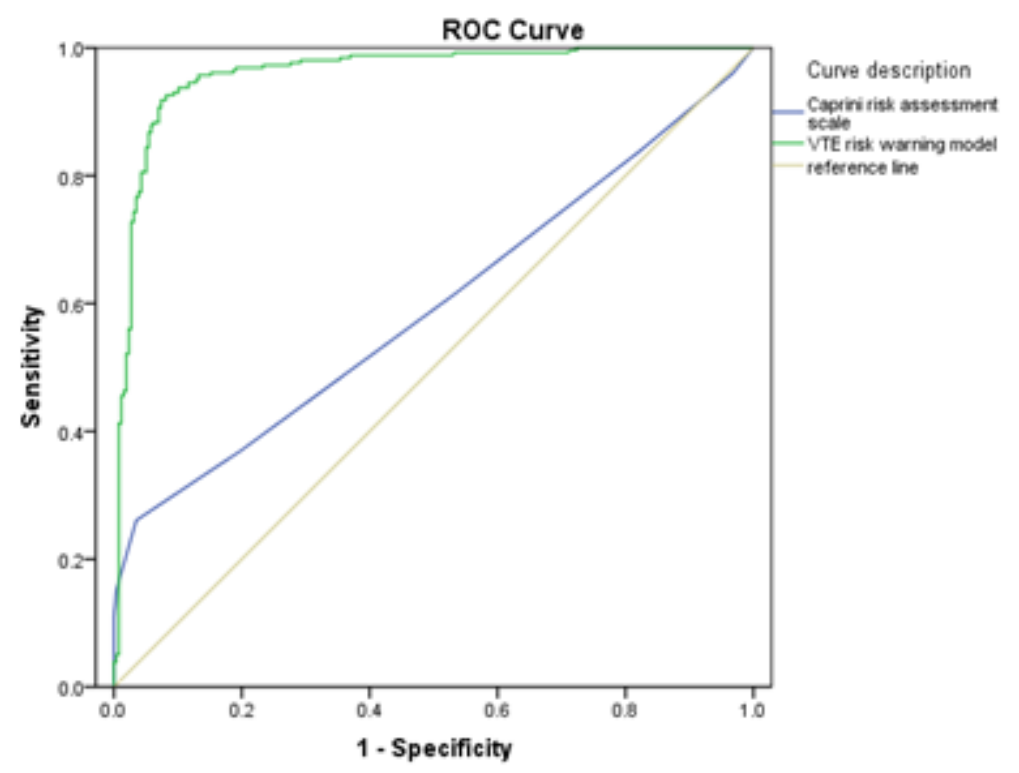

\section{Figure 1}

Comparison of ROC curves of VTE screening by Caprini risk assessment scale and VTE risk warning model

\section{Supplementary Files}

This is a list of supplementary files associated with this preprint. Click to download.

- VTEStatisticaltable.xlsx 